\title{
A anatomia do templo dórico grego: origem e desenvolvimento
}

\author{
The anatomy of the Greek Doric temple: origin and development
}

\author{
Claudio Walter Gomez Duarte*
}

\begin{abstract}
Resumo: Este artigo objetiva abordar a gênese do templo dórico grego até a formação do tipo ou "cânone", dando ênfase para as teorias mais polêmicas que permeiam o assunto. Abordamos a forma do templo dórico, em planta e elevação. Para isso, construímos uma espécie de glossário, só que minuciosamente detalhado, explicando a forma e função de cada elemento arquitetônico que compõe o templo dórico. Explicamos a nomenclatura para a designação de cada tipo de templo com exemplos para cada formação. Finalizamos o artigo com uma lista cronológica dos principais templos dóricos e uma figura que auxilia o entendimento do tipo dórico.
\end{abstract}

\begin{abstract}
This article aims to address the genesis of the Greek Doric temple until the formation of the type or "canon", emphasizing the most controversial theories that permeate the subject. We approach the form of the Doric temple, in plan and elevation. For this, we have built a kind of glossary, minutely detailed, which explains the form and function of each architectural element that makes up the Doric temple. We explain the nomenclature for the designation of each type of temple, with examples for each formation. We finish this article with a chronological list of the main Doric temples and an illustration that helps to understand the Doric type.
\end{abstract}

\author{
Palavras-chave: \\ Arqueologia. \\ Arquitetura grega. \\ Templo dórico. \\ Templo períptero. \\ Ordem dórica.
}

\footnotetext{
* Doutor em Arqueologia pelo Museu de Arqueologia e Etnologia (Mae) da Universidade de São Paulo (Usp) e professor de Arqueologia da Universidade Metropolitana de Santos (Unimes).
} 


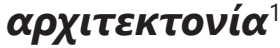

"Sob os climas meridionais, cujo rigor só é aplacado pela sombra e pelo ar, o pórtico é o principal elemento da arquitetura" (CHOISY, 1951, p. 164). Na procura das origens e rudimentos para a arquitetura do templo dórico, foram encontradas vagas semelhanças em termos de elevação e planta. Para o capitel, cogitou-se o parentesco com as ordenações micênicas, nos quais se destacam o ábaco e o toro; e, para o entablamento, com os pórticos egípcios de Beni-Hasán. Em termos teóricos, a teoria mais antiga defende que as formas da ordem dórica derivam de um sistema construtivo em madeira que ao longo do tempo foi substituído por pedra - teoria esta que conta com a autoridade de Vitrúvio (CHOISY, 1951, p. 165-166).

Segundo Étienne, Müller e Prost (2000, p. 131):

[...] depois de observar certas particularidades nos templos dóricos conhecidos, assim como o templo de Apolo em Corinto (aproximadamente 550 a.C.) ou o templo de Posídon em Ísthmia, sem friso com tríglifos e dotado de uma cornija horizontal com a parte inferior nua, conclui que a ordem dórica não é o resultado da petrificação de uma arquitetura em madeira, como sugeriu Vitrúvio, ${ }^{2}$ mas antes uma criação eclética, dependente de condições locais, técnicas, etc.

Em termos de planta, convém observar que:

A descendência às vezes suposta entre o mégaron do palácio micênico e a planta do templo distilo in antis só é fundada sobre uma analogia superficial que satisfaz ao explicar a analogia das funções, sem que se possa demonstrar uma imitação do edifício mais antigo para o edifício mais recente. Sobre a forma que eles lhe deram, o templo é uma criação exclusiva dos gregos. E tornou-se para nós o monumento característico de seus santuários, a ilustração por excelência de seu gênio arquitetural (ROUX, 1961, p. 153).

A introdução de elementos de ordem dórica nos templos gregos ocorre pela primeira vez no final do século VII a.C. e começo do século VI. Sua gênese se encontra no desenvolvimento dos templos primitivos que surgiram no final do século VIII, que são herdeiros, por sua vez, de uma tradição secular residencial precária, pós-palaciana, que se desenvolveu a partir da "Idade das Trevas" (1100-900 a.C.) - num período tido como de pobreza e confusão, mas que, de acordo com as pesquisas arqueológicas das últimas décadas, se trata de um período rico e pleno de luzes. Essa gênese teve dois

\footnotetext{
${ }^{1}$ Vocábulo grego que significa arquitetura e também construção (BAILLY, 1950, p. 282).

${ }^{2}$ Arquiteto romano (final do século I a.C. e começo do I d.C.), autor do livro De Architectura, que "[...] combina várias tradições da teoria arquitetônica grega e sua crítica como engenheiro romano". Único tratado escrito sobre arquitetura que restou da Antiguidade (POLLITT, 1995, p. 284; ÉTIENNE; MÜLLER; PROST, 2000, p. 131).
} 
representantes tipológicos fundamentais para a sua formação: o mégaron B em Thermos, de planta retangular, que se assemelha ao templo distilo in antis e o Herôon de Lefkandi, de planta absidal, em formato de semicírculo, que se assemelha aos templos posteriores pela colunata que o circunda, ambos do século $X$ a.C. Robertson mostra uma relação de 18 edificações, templos e tesouros datados entre os séculos $\mathrm{X}$ e VI a.C. que não permitem nenhuma atribuição definidamente dórica, eólica ou jônica (BIERS, 1992, p. 7; ÉTIENNE; MÜLLER; PROST, 2000, p. 129; LAWRENCE, 1998, p. 61; ROBERTSON, 1997, p. 383-385; BARLETTA, 2001, p.154).

Étienne, Müller e Prost (2000, p. 129-130) observam que:

[...] a diferença do edifício dos chefes e do edifício dos deuses não é feita provavelmente de maneira brusca, e se o mégaron B de Thermos, de planta retangular é aparentemente desprovido de colunas no exterior, teve manifestada a função de um templo bem do início do primeiro milênio. E o Herôon de Lefkandi [...] permite sustentar mais claramente a tese da passagem da casa de um "príncipe" à cela de um deus. [...] [E acrescenta que] o antigo esquema evolutivo conduzia de um edifício grosseiramente semelhante ao mégaron micênico sem peristilo a um edifício retangular com peristilo [e que a essa transição] veio então se substituir uma história mais complexa que leva em conta as descobertas arqueológicas recentes.

Entre os séculos VII e VI a.C., adotando métodos rústicos de construção, os templos "dóricos" primitivos foram construídos com os seguintes materiais: madeira para as colunas, entablamento, umbrais e estrutura do telhado, tijolos secos ao sol para as paredes e pedra bruta para as bases; e o telhado podia ser de colmo ou telhas de terracota. No século VII a.C. desenvolveu-se a noção de construir com pedra lapidada, e acredita-se que seja uma consequência do uso de telhas, cujo peso excedia bastante o peso das telhas modernas (LAWRENCE, 1998, p. 59).

Um templo importante na fase de transição e formação do templo dórico foi o templo de Posídon em Ítsmia, que mesmo tendo sido substituído no início do século $\mathrm{V}$ deixou vestígios suficientes que permitiram uma restauração gráfica feita por Dinsmoor (1950). Este templo se destaca por ter as paredes construídas totalmente em pedra, com uma decoração talhada em forma de painéis que dava um efeito de armação de madeira. Tinha o telhado de terracota em duas águas, colunata circundante em madeira e seu entablamento também de madeira. No mesmo período, e em condições semelhantes, foi construído no local do Heraion de Argos um templo que se supõe ter substituído uma estrutura mais simples. Um pouco mais tarde - aproximadamente em 630 a.C. surge outro templo de suma importância, o períptero de Apolo, em Thermos, que foi construído sobre o mégaron $B$, com as partes superiores em tijolos secos ao sol e colunata circundante de madeira, que mais tarde foram substituídas por colunas de pedra. Sua 
grande importância reside no fato de "[...] seu entablamento de madeira ter sido ornado com painéis de terracota pintados que sobreviveram e, sem dúvida, constituíam um conjunto de métopas - isto é, o templo tinha o friso regular da ordem dórica" (LAWRENCE, 1998, p. 66). Segundo Billot (2008), pesquisas mais recentes, nos últimos quinze anos, revisaram completamente a história desse templo, concluindo-se que se trata de um templo helenístico.

"A proporção geral constitui o índice cronológico mais preciso, já que toda a obra dos gregos leva em suas proporções a impressão de sua data" (CHOISY, 1951, p. 169). Os templos dóricos gregos foram construídos, sucessivamente, entre os séculos VII e II a.C. ${ }^{3}$ (ROBERTSON, 1997, p. 385-391), e correspondem convencionalmente aos seguintes períodos da civilização helênica: Arcaizante [700-480 a.C.], Clássico [480-323 a.C.] e Helenístico [323-30 a.C.] (BIERS, 1992, p. 7). É muito difícil estabelecer com precisão qual foi o primeiro templo dórico construído e qual foi o último. A Arqueologia é uma ciência que está em plena atividade, e lida constantemente com novos achados e evidências, que trazem à tona a discussão e a reorganização cronológica da cultura material. Existem várias listas de templos gregos, mas nenhuma completa. Muitas delas privilegiam os templos de maior prestígio (DINSMOOR, 1950, p. 341-342). Existem também as enciclopédias, ${ }^{4}$ e os sites oficiais de sítios arqueológicos, ${ }^{5}$ que trazem inventários dos monumentos, mas não trazem uma lista específica e completa dos templos gregos. Um livro importante estabelece uma catalogação "completa" dos templos gregos à luz das escavações mais recentes. Trata-se de The complete Greek temples, trabalho do pesquisador Tony Spawforth, de 2006. Embora constitua um grande passo, muito útil, abrangente e bem ilustrado, restringe-se à catalogação dos templos perípteros (ou seja, rodeados por colunata) deixando de fora outras tipologias importantes como o templo in antis, o templo prostilo e o anfiprostilo.

Do ponto de vista estrutural, para alguns autores, os templos eram superdimensionados. Essa opinião merece uma revisão, pois a estrutura robusta poderia ser o partido arquitetônico adotado para explorar o aspecto monumental da edificação, e Billot (2008) muito bem observa: "superdimensionados em relação ao quê?". Para autores como Dinsmoor (1950), os construtores gregos eram tímidos engenheiros. Essas estruturas exigiriam da pedra uma parte mínima do esforço que poderiam suportar. O calcanhar de Aquiles dos templos é a disposição da colunata, que conspira contra a sua estabilidade - pois, ao ser coroada pela pesada massa do entablamento, levanta o centro de gravidade do edifício, tornando-o vulnerável aos tremores de terra. A maior parte

\footnotetext{
${ }^{3}$ Para autores mais recentes, o dórico é datado em 600 a.C.

${ }^{4}$ Vide, Stillwell (1979).

${ }^{5}$ Consultar, por exemplo, <https://www.culture.gov.gr>
} 
dos templos gregos pereceu por causa de abalos sísmicos. Vários outros, ainda, foram destruídos durante as guerras e alguns foram desmontados para reciclar seu material para uso em outras edificações. Uns poucos permaneceram com a sua estrutura íntegra como o Heféstion de Atenas, o templo da Concórdia em Agrigento e alguns outros (CHOISY, 1951, p. 156-157).

Eis mais algumas informações a que precisamos estar atentos:

Assim, quando [a civilização grega] passou a construir seus templos [em pedra] se ateve ao esquema de suas primeiras estruturas de madeira, ou seja, o mais [simples] dos partidos arquitetônicos possíveis: planta retangular, telhado de duas águas com frontões nos topos, colunas e arquitrave, ou viga-mestra. Tudo sempre na base da contenção e da verga reta (COSTA, 1980, p. 9).

[...] a forma e a aparência essencial foram obra do século VII, no final do qual a obra foi executada em pedra e os detalhes estruturais sofreram as modificações correspondentes. Uma vez feito isso, na primeira parte do século $\mathrm{Vl}$, o templo dórico estava essencialmente formado, e embora se seguissem muitas modificações e refinamentos, tanto em minúcias quanto em método de projetar, não houve nenhuma alteração significativa na concepção (LAWRENCE, 1998, p. 67).

Uma organização tipo terminou por se impor, feita de um pronaos, de uma cela e de um opistódomo, e as modificações desta planta base se explicam seja por uma tradição regional, como por exemplo na Magna Grécia, aonde muitos templos apresentam ádito no fundo da cela, seja por razões religiosas (ÉTIENNE; MÜLLER; PROST, 2000, p. 130).

\section{Tipologia: planta e elevação: elementos ${ }^{6}$}

Planta: elementos

Atualmente entendemos por planta um corte imaginário paralelo ao piso, feito no volume arquitetônico passando a uma distância de 1,40 m por convenção e em escala. Esse corte mostra a distribuição das dependências do edifício por andar e nos dá acesso a uma parte importante das informações sobre determinada edificação. Para os templos gregos, podemos dividir de modo prático os elementos da planta em dois grupos:

a) Dependências: pronaos, cela, opistódomo, ádito e pteroma;

b) Elementos associados: eutintério, crepidoma, rampa, estilóbato, plataforma, peristilo, pórticos internos, vãos de circulação (abertura para portas e intercolúnios) e desníveis entre dependências ou elementos.

\footnotetext{
${ }^{6} \mathrm{~A}$ composição dos verbetes de anatomia do templo dórico foi elaborada com base na revisão das mais relevantes fontes bibliográficas, textos e glossários seguintes: Choisy (1951, p. 164-183), Coulton (1977, p. 189-191), Dinsmoor (1950, p. 388397); Fletcher (1950, p. 84-89), Ginovuès (1992; 1998), Ginovuès e Martin (1985), Hellmann (1998, p. 213-218; 2002; 2006), Höcker (2008), Lawrence (1998, p. xiv-xv; 66-76), Robertson (1997, p. 447-465); Tomlinson (1989, p. 102-104).
} 
Podemos também traduzir a planta do templo grego em função de suas dependências e montar um quadro que atenda às tipologias mais conhecidas para entendermos a lógica de suas variações.

a) Pronaos e cela;

b) Pronaos, cela e pteroma;

c) Pronaos, cela e opistódomo;

d) Pronaos, cela, opistódomo e pteroma;

e) Pronaos, cela, ádito e pteroma;

f) Pronaos, cela, ádito, opistódomo e pteroma.

PRONAOS: conhecido também por vestíbulo, é uma antessala ou hall, provida de um pórtico que dá acesso à cela.

CELA: é a sala sagrada principal do templo ou santuário, onde se colocava a estátua cultual. Também é conhecida como nave. A cela pode ter ou não colunata interna; geralmente tem quando a largura da cela é grande, pois a colunata serve de apoio à estrutura do telhado. Quando tem colunata interna, a cela é dividida em naves.

- Base da estátua de culto: apoio retangular, nos casos conhecidos. Provavelmente na maioria dos templos deve ter se situado no fundo da cela. No Partenon e no templo de Zeus, em Olímpia, se pode reconhecer o lugar que ocupava a estátua, pois existe no local uma fundação maciça. Salientamos que a base da estátua não faz parte da planta e sim do equipamento do templo.

ÁDITO: sala sagrada (santuário recôndito) localizada no fundo da cela, de acesso restrito aos sacerdotes do templo.

OPISTÓDOMO: sala aberta, localizada no fundo do templo; é uma réplica do pronaos. Funcionava como tesouro e era um lugar para colocar oferendas. Algumas vezes era fechado por grades de bronze. Normalmente, não se comunicava com a cela.

PTEROMA: é a passagem ou galeria formada entre as paredes da cela e a colunata exterior ou peristilo.

EUTINTÉRIO: é um alinhamento de blocos de pedra (fiada de nivelamento) enterrada ou pouco visível, aonde se assenta a crepidoma, interface entre os alicerces e a superestrutura visível. O eutintério forma um retângulo que define os limites da edificação, e esse termo é muito utilizado entre os pesquisadores para referir-se às dimensões totais de largura e comprimento dos templos.

CREPIDOMA: é formado por três degraus externos que rodeiam todo o templo. ${ }^{7}$ No caso do templo períptero, estes dão acesso à plataforma do templo. No século VI, estes

\footnotetext{
${ }^{7}$ Normalmente, é composto por três degraus, mas há exemplos com quatro, dois e somente um.
} 
degraus podiam utilizar-se normalmente, pois eram construídos de acordo com a escala humana independentemente das dimensões do templo (com exceções). Mais tarde, no século $V$, foram dimensionados em relação às proporções do templo, e nos templos de grande porte tiveram de ser complementados por degraus intermediários ou rampa para possibilitar o acesso, passando o crepidoma a ter uma função ornamental. $\mathrm{O}$ terceiro degrau do crepidoma se chama estilóbato.

ESTILÓBATO: é o degrau superior do templo, o qual serve de plataforma de apoio para o peristilo ou colunata exterior. Este termo é usado erroneamente por alguns autores para designar os três degraus ou crepidoma. Normalmente, as dimensões externas da planta de um templo, sem contar os dois primeiros degraus, são dadas pela largura e comprimento exterior do estilóbato. Exemplo: as dimensões do estilóbato do templo de Hera em Olímpia são 18,75 m x 50,01 m.

RAMPA: é um plano inclinado de acesso que leva direto à plataforma do templo. É comum a vários templos, como por exemplo: o templo de Apolo em Delfos, o templo de Aphaia em Egina e o templo de Asclépio em Epidauro.

PLATAFORMA: embasamento sólido, onde se apoiam a estrutura ou colunata e as paredes do templo.

PERISTILO: nome dado à colunata que rodeia o templo. Para sabermos quantas colunas tem um templo em uma determinada fachada, sempre contamos as colunas de esquina ou de ângulo. Quando dizemos, por exemplo, que o templo de Hefestos possui um peristilo de $6 \times 13$, queremos dizer que este edifício tem seis colunas na fachada principal e posterior e tem treze colunas em cada fachada lateral. No entanto, quando contamos desta maneira, temos a falsa impressão de que o templo tem 38 colunas em seu peristilo, mas na realidade ao consultarmos a planta verificamos que a quantidade real de colunas são 34 e não 38. Isso acontece pois, por convenção, sempre contamos duas vezes a mesma coluna de ângulo para facilitar a leitura das quatro fachadas do templo.

COLUNATA INTERNA: fileira de colunas no interior da cela (define o layout e o número de naves ou naos). Sua função estrutural é suportar o peso do telhado e sua estrutura.

\section{VÃOS DE CIRCULAÇÃO}

- Portas: são as únicas aberturas nas paredes, normalmente encontradas nos templos e demais edifícios dóricos. Localizam-se na entrada da cela e, no caso de o templo ter ádito e opistódomo, a porta pode ter o acesso direto via cela ou pelo opistódomo. Nos templos do tipo pronaos, cela e opistódomo, normalmente, não têm porta de ligação entre o opistódomo e a cela, mas também há exceções. 
- Intercolúnios: é o nome dado às distâncias de eixo a eixo entre as colunas dos pórticos e entre os quais temos os vãos de circulação.

Elevação: ordem dórica: elementos

Um templo grego é, quase invariavelmente em termos de elevação, um pórtico sobre colunas; os edifícios civis, os mercados e lugares de reunião, estão rodeados de pórticos. [...]. Sob a disposição dos pórticos [...] concentram seus esforços. Solucionando [assim, seu] programa arquitetônico na base de duas ordens [a dórica e jônica] (CHOISY, 1951, p. 164).

Esquematicamente, temos:

CREPIDOMA - COLUNA - ENTABLAMENTO - FRONTÃO.

CREPIDOMA

- Degraus.

COLUNA

- Partes: fuste, capitel (equino e ábaco);

- Detalhes: fuste (caneluras, arestas, perfil), capitel (gola, aneletes).

ENTABLAMENTO

- Partes: arquitrave e friso;

- Detalhes: friso [regula, tênia, tríglifo, métopa (lugar para baixos relevos), mútulo, cornija horizontal].

\section{ORDEM}

- Altura do conjunto de elementos arquitetônicos formado por coluna e entablamento. ${ }^{8}$ FRONTÃO

- Partes: tímpano e cornija inclinada;

- Detalhes: esculturas apoiadas na cornija horizontal do entablamento, cornija inclinada (acrotérios).

COLUNA: é composta por dois elementos estruturais de pedra, o fuste e o capitel. 0 fuste desprovido de base se apoia diretamente no piso - a base se reduz a casos excepcionais dentro da ordem dórica. O capitel concentra os esforços transmitidos pela arquitrave, e o fuste os absorve e transfere ao embasamento do edifício. As proporções das colunas foram modificadas com o passar do tempo e as suas alturas variaram em termos gerais em intervalo de 4 a 6 1/2 vezes o diâmetro da "base"; assim, o diâmetro do topo do fuste diminui em intervalo de 3/4 a 2/3 em relação

${ }^{8}$ Por exemplo: o templo de Zeus, em Olímpia, tem uma ordem de 14,595 m (a altura da coluna é 10,430 m e a altura do entablamento é 4,165 m). 
ao diâmetro da "base". As colunas interiores do templo, tanto as do pórtico do pronaos quanto as localizadas no interior da cela, são normalmente mais esbeltas e podem vir a apresentar algumas diferenças em relação às exteriores, como por exemplo ter um número menor de caneluras ou um perfil mais fechado no equino do capitel.

FUSTE: podem ser monolíticos (os mais antigos) ou compostos pela sobreposição de vários blocos ou tambores fixados uns aos outros por meio de cavilhas ou empólios de madeira. Os tambores podem ter sido trabalhados no formato arredondado, como sugerem os vestígios deixados em algumas pedreiras, ou podem ter adquirido esta forma através do uso do torno. As características geométricas do fuste são seu perfil e as caneluras.

- Perfil: o fuste ou haste tem normalmente um ligeiro perfil convexo chamado êntases. No período arcaico, esta curvatura foi bem acentuada, e o diâmetro decresceu desigualmente e de forma rápida.

- Caneluras: são incisões côncavas rasas em formato de arco de circunferência feitas ao redor do fuste e acompanhando todo seu perfil, formando assim um feixe de arestas vivas. Eram cinzeladas depois que a estrutura do edifício estivesse pronta para diminuir os riscos de danos ao perfil e garantir o alinhamento das arestas, o que seria muito difícil se fossem esculpidas em tambores separados. Obras inacabadas mostram que a indicação das caneluras era feita antes de erguer o fuste, somente no tambor inferior, para assegurar a colocação correta. A quantidade de caneluras variava, havendo exemplos com 12, 16, 18 e 24, mas estabeleceu-se de modo padrão com 20, certamente atribuído a vantagens de ordem estética.

CAPITEL: é composto por dois membros esculpidos em um só bloco, o ábaco e o equino. Do ponto de vista ornamental se trata de uma solução que estabelece certa continuidade entre as linhas retas do entablamento e a seção circular do fuste.

- Ábaco: é o membro superior do capitel e elemento de transição entre a arquitrave e o equino. A partir da época do Partenon perde sua função estrutural de sustentáculo, como tinha no período arcaico; e, para prevenir sua ruptura, suas bordas foram isoladas da arquitrave, deixando um espaço vazio de cada lado que se encontra com o alinhamento do fuste, passando a ter uma função ornamental. De modo simples, sua geometria é a de um paralelepípedo de base quadrada e pequena altura. O lado da base do ábaco tem sempre o mesmo comprimento que o diâmetro do topo do equino, enquanto o perfil do ábaco e do equino chegaram a ter praticamente a mesma altura nos exemplos mais antigos do final do século VII e começo do século VI. 
- Equino: é o membro inferior do capitel e a parte que se encaixa no topo do fuste. Seu perfil se assemelha a uma curva parabólica que se espraia para fora até fazer a transição com a laje achatada ou ábaco. Este perfil curvo foi bem acentuado no período arcaico e foi se suavizando com o passar do tempo. Ao endireitarmos a curva melhoramos o problema estático, pois a carga proveniente da arquitrave se distribui na saliência do capitel. Visando à solução dos problemas estruturais envolvidos, o perfil curvo vai se enrijecendo até tomar o aspecto de uma linha quase reta, atingindo uma inclinação exata de $45^{\circ}$ no caso do templo de Hefesto em Atenas. A transição entre o último tambor do fuste e o equino se faz através de uma fatia de tambor que é esculpida no capitel e é limitada, tanto na parte superior como na inferior, por um grupo de aneletes ou listéis horizontais. Esse detalhe de junção se prestou a muitas variações, tanto no número de aneletes, que variou de 3 a 5, como nos detalhes de chegada do feixe das caneluras provindas do fuste.

ANTA: é uma pilastra que constitui um apoio para a parede e está associada à sua terminação. Não se estabeleceu de forma precisa em nenhum período. Sua forma é a de uma haste de seção quadrada com acabamentos variados para seu capitel.

ENTABLAMENTO: é a superestrutura que se apoia diretamente sobre as colunas e é formado pela associação de três elementos: arquitrave, friso e cornija. Compõe as elevações do edifício, e se posiciona nas fachadas principais entre a colunata e o frontão e nas fachadas laterais entre a colunata e a parte inferior do telhado. Chega a ocupar $1 / 4$ da altura da elevação principal e é responsável por absorver boa parte da carga que provém da estrutura do telhado e transferi-la à colunata.

- Arquitrave: é o nome dado a uma viga ou lintel. Quando se trata da arquitrave em relação ao entablamento, se refere ao conjunto de vigas ou lintéis que, alinhados e apoiados sobre a colunata, suportam os membros superiores do entablamento. A arquitrave de pedra não é uma viga contínua que se estende por toda a colunata, e sim composta de várias partes. Sua geometria é a de um paralelepípedo de base retangular e pouca altura. O comprimento de cada parte é igual à distância entre os eixos a cada duas colunas ou intercolúnio. A arquitrave nos templos mais antigos era monolítica, mas, no século $V$ a.C., há uma tendência a substituir o monobloco por duas ou três peças unidas entre si. Este novo sistema se torna mais econômico e seguro do ponto de vista estrutural. O alinhamento da arquitrave em relação ao topo do fuste variava: há exemplos onde estão aprumados e também onde a arquitrave avança e também recua a este alinhamento. Dois elementos que compõem a arquitrave são a tênia e a régula. 
- Tênia: é um filete de pedra esculpido no topo da própria arquitrave que acompanha toda a extensão da fachada, projetando-se para fora. É um elemento de transição entre a arquitrave e o friso.

- Régula: é uma estreita tira de pedra localizada debaixo da tênia e alinhada com a largura do tríglifo. Em sua base são esculpidas uma fileira de seis gotas ou pequenos cilindros.

- Friso: localizado entre a cornija e a arquitrave, é composto de uma sucessão de tríglifos e métopas alternados. Normalmente são elementos independentes, mas às vezes eram esculpidos em um bloco só (ou seja, um tríglifo e uma métopa juntos). $O$ friso absorve os esforços transmitidos pelo frontão através da cornija. Tem a função de elevar a base do frontão e é um elemento decorativo característico da ordem dórica. A distribuição desses elementos no friso é feita da seguinte forma: para cada coluna há um tríglifo alinhado com o seu eixo (exceção para os tríglifos de esquina, que não estão alinhados com o centro da coluna) e um tríglifo centralizado entre duas colunas. Entre dois tríglifos intercala-se uma métopa. Esta distribuição vale para o período arcaico e clássico, com exceções. Já no período helenístico se usam normalmente dois tríglifos entre colunas, aumentando assim o intercolúnio. Sempre as extremidades do friso são compostas de tríglifos.

- Tríglifos: são pequenos pilares monolíticos que possuem nas laterais cavidades onde encaixam as métopas. Sua geometria é a de um prisma reto de base retangular, e em sua face estão esculpidas duas caneluras no centro e meias caneluras nas extremidades. Os detalhes das incisões e dos perfis são variados. O tríglifo de ângulo é um dos grandes problemas na concepção do friso, pois sua largura e seu alinhamento podem sofrer alterações em relação aos outros.

- Métopas: são lousas retangulares de pedra fixadas entre os tríglifos e recuadas em relação ao seu alinhamento. As mais antigas eram feitas de terrracota. São espaços frequentemente destinados à representação de figuras em baixo relevo e fazem parte da escultura arquitetônica. Em alguns templos são lisas, sem representação. A métopa que se localiza ao lado do tríglifo de ângulo tem também a sua largura alterada em consequência do problema que gera o tríglifo de ângulo comentado no item anterior.

- Cornija: é o membro superior do entablamento e se trata de um perfil que se projeta para frente e se apoia no friso. Tem a função de afastar as águas pluviais do alinhamento das fachadas do edifício. A cornija horizontal de frontão tem também a função de apoiar as estátuas em alto-relevo e é composta, em sua parte inferior, pelo mútulo. Não possui calha. Já a cornija lateral possui uma cimalha ou calha 
que recebe as águas pluviais vindas do telhado e são coletadas em seu canal e escoadas através de orifícios feitos em várias partes da calha. Estes orifícios ou canais eram decorados com cabeças de leão e com palmetas, conhecidos com o nome de gárgulas.

- Mútulos: encontram-se na face inferior das cornijas (horizontal e inclinada) e são de caráter decorativo. Têm o aspecto das régulas, só que são mais largos e possuem normalmente três fileiras de seis gotas. Estão distribuídos entre os tríglifos e as métopas, correspondendo um a cada elemento do friso.

FRONTÃO: é um acabamento triangular dado às arestas do telhado. Este se apoia no entablamento da fachada frontal e posterior do templo. É composto pelo tímpano, parede triangular cercada pela cornija horizontal, e a cornija inclinada (que difere da cornija horizontal lateral pela ausência de mútulos e gárgulas). A inclinação do frontão acompanha a inclinação do telhado. O espaço criado no frontão ou pedimento foi usado em muitos templos para acomodar uma série de esculturas que formam parte do grupo de esculturas arquitetônicas. A decoração do frontão por meio de estátuas é uma prática que remete ao arcaísmo. Outros elementos decorativos que se apoiam nas extremidades e no ápice do frontão são os acrotérios, que podem ser grifos, ornamentos ou estátua no ápice.

TELHADO: em duas águas, composto por uma estrutura de madeira coberta de telhas de terracota ou mármore. Do ponto de vista estrutural, funcionava de forma radicalmente diferente de nossas estruturas modernas. O sistema grego trabalhava por esmagamento ou flexão de seus elementos, e nunca por tração, como funcionam as atuais tesouras (treliças); isso constituía uma grande desvantagem para vencer grandes vãos. Os telhados precisavam de vigas mestras com grandes seções, o que impossibilitou a cobertura de templos de grande porte - como o templo de Apolo em Didima, segundo o testemunho de Estrabão.

ANTEFIXAS: ornamentos verticais de acabamento (com motivos florais) distribuídos ao longo da cornija, diretamente sobre a sima (calha de escoamento das águas pluviais provenientes do telhado). Originalmente, nos edifícios que não possuíam sima, as antefixas eram usadas para esconder as extremidades das telhas de junção intercaladas entre as telhas planas de escoamento. Às vezes eram colocadas também no topo do telhado (na aresta divisora das águas). 


\section{Classificação dos templos}

Os vários arranjos das colunas na planta de um templo receberam nomes especiais e podemos utilizar a nomenclatura de Vitrúvio para auxiliar na identificação de cada tipo de templo (FLETCHER, 1950, p. 83).

- GERAL: 9 in antis, prostilo, anfiprostilo, períptero, díptero, pseudoperíptero, pseudodíptero;

- PARTICULAR: ${ }^{10}$ Para nomear um templo ou um tipo de templo em particular combinamos

as formas gerais acima com os prefixos gregos ou latinos: heno ( $\mathrm{gr}$. hena $=1$ ), di (gr. dís = duas vezes, em dobro), tri (gr. lat. tri $=3)$, tetra (gr. tetrá $=4)$, penta (gr. pénte $=5)$, hexa (gr. héx $=6)$, hept (gr. heptá $=7$ ), octo (gr. októ, lat. octo $=8)$, enea (gr. enea = 9), deca (gr. déka = 10), dodeca (gr. dódeka =12).

Segue a classificação de tipos específicos de templos com as devidas explicações e exemplos: ${ }^{11}$

I - Henostilo in Antis: templo primitivo com pórtico frontal composto apenas de uma coluna entre antas. Exemplo: Templo "A" em Prinias (dórico).

II - Distilo in Antis: Formado por duas colunas entre antas somente no pórtico da fachada frontal. É uma das formas mais simples e comuns de templo. Exemplo: Templo de Têmis ou Nêmesis em Ramnunte (dórico) e o Heraion dórico de Delos (SARIAN, 2000, p. 330).

III - Anfidistilo in Antis: da mesma forma que em II (Distilo in Antis), só que repetindo o pórtico na fachada posterior do edifício. Exemplo: Templo de Ártemis em Elêusis (dórico).

IV - Tristilo in Antis: formado por três colunas entre antas somente no pórtico da fachada frontal. Exemplo: Hecatompedon em Atenas (dórico).

V - Tetrastilo in Antis: como em II (Distilo in Antis), só que com quatro colunas entre antas no pórtico da fachada frontal. Exemplo: Templo de Ártemis em Lusoi (dórico).

VI - Tetrastilo Prostilo: formado por um pórtico de quatro colunas somente na fachada principal. Exemplo: Templo "B" de Selinunte, Sicília e o templo de Dioniso em Pérgamo (dóricos).

\footnotetext{
9 "A disposição da colunata ao redor dos templos deu lugar à seguinte nomenclatura: prostilo, templo com pórtico frontal somente; anfiprostilo, com pórticos na parte frontal e traseira; períptero, com colunatas laterais que conectam os pórticos dianteiro e traseiro; pseudoperíptero, quando se substituem estas colunatas laterais por pilastras ou colunas em relevo; díptero, quando as colunatas laterais são duplas [distribuição tipicamente jônica, sem exemplos para a ordem dórica]; pseudodiptero, quando está planejado como díptero mas falta a fila interior de colunas" (ROBERTSON, 1997, p. 86). Para Summerson (1996, p. 161-163), "[...] constitui a maior aproximação do estilo dórico com os esquemas dípteros jônicos [...]". ${ }^{10}$ Ver Dinsmoor (1950, p. 396-397).

${ }^{11}$ Consultar Dinsmoor (1950, p. 340-341; p. 396-397), Fletcher (1950, p. 83), Robertson (1997, p. 385-391; 447-465).
} 
VII - Tetrastilo Anfiprostilo: da mesma forma que em VI (Tetrastilo Prostilo), só que repetindo o pórtico de quatro colunas na fachada posterior. Nessa família de termos compostos, o prefixo anfi- implica que a mesma forma é utilizada na parte anterior e posterior. Exemplo: Templo de Ártemis Propilaea em Elêusis (dórico).

VIII - Tetrastilo Períptero: templo rodeado de colunas, com quatro colunas tanto no pórtico da fachada frontal como no pórtico da fachada posterior. Exemplo: Templo de Apolo em Cízico e o Monumento das Nereidas em Xantos (jônicos). Desconheço exemplos na ordem dórica para esta disposição de colunata.

IX - Tetrastilo Pseudoperíptero: templo rodeado de meias colunas ligadas às paredes da cela nas fachadas laterais, com quatro colunas no pórtico da fachada frontal e posterior. Exemplo: Templo em Cnido (coríntio). Desconhecemos exemplos na ordem dórica para esta disposição de colunata.

$X$ - Pentastilo Períptero: templo rodeado de colunas, com cinco colunas tanto na fachada principal como na posterior. Exemplo: Templo de Apolo em Thermon (dórico).

XI - Hexastilo Prostilo: da mesma forma que em VI (Tetrastilo Prostilo), só que com seis colunas no pórtico da fachada frontal. Exemplo: Templo dos Cabires em Samotrácia e Templo em Calcário (Atena), Delfos (dóricos).

XII - Hexastilo Anfiprostilo: da mesma forma que em VII (Tetrastilo Anfiprostilo), no entanto os seus pórticos contêm seis colunas. Exemplo: Templo de Apolo (dos Atenienses) em Delos (dórico).

XIII - Hexastilo Períptero: podemos dizer que é a forma adotada pelos templos dóricos de maior prestígio. Este tipo de templo é rodeado de colunas, com seis delas tanto no pórtico da fachada frontal como no pórtico da fachada posterior. Em relação ao número de colunas das fachadas laterais variou muito (entre 10 e 17 colunas), mas no período clássico se encontram vários exemplos com a seguinte regra: multiplicava-se por dois o número de colunas da fachada principal e se acrescentava uma para calcular o número de colunas das fachadas laterais (conhecida como dórico pericliano). Exemplo: Templo de Posídon em Pesto, Templo de Apolo em Bassai (dóricos) e vários outros.

XIV - Heptastilo Pseudoperíptero: trata-se de um templo rodeado de meias colunas ligadas às paredes da cela em todas as fachadas. Exemplo: Templo de Zeus em Agrigento (dórico). Este exemplo mostra um número não usual de colunas na fachada principal, com sete colunas entre outras singularidades.

XV - Octastilo Períptero: similar ao XIII (Hexastilo Períptero) com a diferença de possuir oito colunas tanto no pórtico da fachada frontal como no pórtico da fachada posterior. Exemplo: O Partenon de Atenas (dórico). 
XVI - Octastilo Díptero: é uma modalidade que não tem exemplos na ordem dórica, tendo exemplos somente para as ordens jônica e coríntia na arquitetura grega. É um templo rodeado por dupla fileira de colunas, com oito delas, tanto na fachada principal como na fachada posterior. Exemplo: o Olimpieion de Atenas (coríntio) e o Templo de Ártemis, em Éfeso (jônico).

XVII - Octastilo Pseudodíptero: possui a planta semelhante ao diptero octastilo, porém é omitida a segunda fileira de colunas, ficando um espaço maior entre a cela e a colunata - espaço este que corresponderia a uma fileira de colunas. Exemplo: Templo "G" de Selinunte, na Sicília (dórico).

XVIII - Eneastilo Prostilo: Como VI (Tetrastilo Prostilo), só que com nove colunas no pórtico da fachada frontal. Exemplo: o Antigo Telestérion de Elêusis (dórico).

XIX - Eneastilo Períptero: similar ao XIII (Hexastilo Períptero) com a diferença de possuir nove colunas tanto no pórtico da fachada principal como no pórtico da fachada posterior. Trata-se de um arranjo não usual. Exemplo: a Basílica de Pesto (dórico). XX - Decastilo Díptero: sem exemplo na ordem dórica. Sua planta é semelhante ao díptero octastilo, com a diferença de possuir dez colunas na fachada frontal e na posterior. Exemplo: o templo jônico de Apolo Didimeu em Didima-Mileto.

XXI - Dodecastilo Prostilo: como o VI (Tetrastilo Prostilo), só que com doze colunas na fachada frontal. Exemplo: Telestérion em Elêusis (dórico).

\section{Considerações finais}

Este é um artigo com caráter teórico e instrumental, que constitui um guia útil para o entendimento de questões fundamentais relativas à formação e desenvolvimento arquitetônico dos templos dóricos gregos. Acreditamos que o material apresentado será de grande valia tanto para o arqueólogo clássico como para o arquiteto, e também para o historiador da arte de construir. Aqui, não tratamos de defender uma tese em específico, mas pretendemos apresentar uma síntese articulada, atualizada e com contribuição proveniente dos diversos saberes relevantes para os estudos da gênese do templo dórico grego. Valorizamos a apresentação das minúcias de cada elemento arquitetônico em elevação e em planta, constituindo assim uma ferramenta importante para o pesquisador que pretenda se debruçar sobre este tema. Finalizamos com uma exaustiva lista de classificação dos templos em relação à quantidade de colunas na elevação, que se aplica a qualquer ordem arquitetônica, por exemplo, dórica, jônica e coríntia. 


\section{Referências}

\section{Obras de referência}

BAILLY, A. Dictionnaire Grec Français. Paris: Librarie Hachette, 1950.

GINOUVÈS, R. Dictionaire méthodique de l'architecture grecque et romaine: éléments constructifs, supports, couvertures, aménagements intérieurs. Rome: École Française de Rome, 1992. v. 3.

GINOUVÈS, R. Dictionnaire méthodique de l'architecture grecque et romaine: espaces architecturaux, bâtiments et ensembles. Rome: École Française de Rome, 1998. v. 3.

GINOVUÈS, R.; MARTIN, R. Dictionnaire méthodique de l'architecture grecque et romaine: matériaux, techniques de construction, techniques et formes du décor. Rome: École Française de Rome, 1985. v. 1.

HÖCKER, C. Metzler lexikon antiker architektur: sachen und begriffe. Stuttgart: J. B. Metzler, 2008.

STILLWELL, R. (Ed.). The Princeton encyclopedia of classical sites. Princeton: Princeton University Press, 1979.

SUMMERSON. J. El lenguaje clásico de la arquitectura. Barcelona: Gustavo Gili, 1996.

\section{Obras de apoio}

BARLETTA, B. The origins of Greek architectural orders. New York: Cambridge University Press, 2001.

BIERS, W. R. Art, artefacts and cronology in classical archaeology. London: Routledge, 1992.

BILLOT, M-F. Compte rendu du mémoire de qualification de Maîtrise de Claudio W. Gomez Duarte. p. 1-2, 2008.

CHOISY, A. Historia de la arquitetura. Buenos Aires: Víctor Leru, 1951.

COSTA, L. Arquitetura. Rio de Janeiro: Bloch/FENAME, 1980.

COULTON, J. J. Greek architects at work: problems of estructure and design. New York: Cornell University Press, 1977.

DINSMOOR, W. B. The architecture of ancient Greece. London: Batsford, 1950.

DUARTE, C. W. G. Geometria e aritmética na concepção dos templos dóricos gregos. 2010. Dissertação (Mestrado em Arqueologia) Museu de Arqueologia e Etnologia da Universidade de São Paulo, Universidade de São Paulo, São Paulo, 2010. 
DUARTE, C. W. G. "Elegância" e "Sutileza" na concepção dos templos dóricos gregos. 2015. Tese (Doutorado em Arqueologia) - Museu de Arqueologia e Etnologia da Universidade de São Paulo, Universidade de São Paulo, São Paulo, 2015.

DUARTE, C. W. G. O que ler para entender a arquitetura dos templos dóricos gregos: uma organização bibliográfica sistemática com introdução para mais de um século de pesquisa. Heródoto, v. 2, n. 1, p. 303-322, 2017.

ÉTIENNE, R.; MÜLLER, C.; PROST. F. Archéologie historique de la Grèce antique. Paris: Ellipses, 2000.

FLETCHER, B. A history of architecture: on the comparative method. London: Batsford, 1950. HELLMANN, M.-Ch. L' Architecture grecque. Paris: Librairie Générale Française, 1998.

HELLMANN, M.-Ch. L'Architecture grecque 1: les principes de la construction. Paris: Picard, 2002.

HELLMANN, M.-Ch. L'Architecture grecque 2: architecture religieuse et funérarie. Paris: Picard, 2006.

LAWRENCE, A. W. Arquitetura grega. São Paulo: Cosac \& Naify Edições, 1998.

POLLITT, J. J. The art of Greece: sources and documents. New York: Cambridge University Press, 1995.

ROBERTSON, D. S. Arquitetura grega e romana. São Paulo: Martins Fontes, 1997.

ROUX, G. L'architecture de l'Argolide aux IVe et IIle s. avant J.-C. Paris: Boccard, 1961.

SARIAN, H. Alguns dados relativos ao projeto de pesquisa "Arqueologia de um santuário: o Heraion de Delos, Grécia". Revista do Museu de Arqueologia e Etnologia, n. 10, p. 329-336, 2000.

SPAWFORTH, T. The complete Greek temples. London: Thames \& Hudson, 2006.

TOMLINSON, R. A. Greek architecture. London: Bristol Classical Press, 1989. 
Figura 1 - Tabela com a lista cronológica de templos dóricos ${ }^{12}$

\begin{tabular}{|c|c|c|c|c|c|c|c|c|c|}
\hline $\begin{array}{l}\text { Datas } \\
\text { (a.c.) }\end{array}$ & $\begin{array}{l}\text { Datas } \\
\text { termino }\end{array}$ & $\begin{array}{l}\text { Pals } \\
\text { atual }\end{array}$ & $\begin{array}{c}\text { Cidade onde } \\
\text { está localizado }\end{array}$ & $\begin{array}{c}\text { Nome do } \\
\text { templo }\end{array}$ & $\begin{array}{l}N^{2} \text { de } \\
\text { colunas }\end{array}$ & $\begin{array}{c}\text { Estilobato } \\
\text { dimensöes } \\
\text { (m) }\end{array}$ & $\begin{array}{c}\text { Antura } \\
\text { coluna } \\
(\mathrm{m})\end{array}$ & $\begin{array}{l}\text { Altura } \\
\text { entab. } \\
\text { frontal }\end{array}$ & $\begin{array}{l}\text { Altura } \\
\text { entab. } \\
\text { lateral }\end{array}$ \\
\hline 590 & & Grécia & Olimpia & Heraion & $6 \times 16$ & $18,750 \times 50,010$ & 5,220 & $?$ & $?$ \\
\hline 565 & & Itália & Siracusa & Apolo & $6 \times 17$ & $21,570 \times 55,330$ & 7,980 & $?$ & $?$ \\
\hline 555 & & Itália & Siracusa & Olimpieion & $6 \times 17$ & $22,400 \times 62,050$ & ca. 8,000 & $?$ & $?$ \\
\hline 550 & 530 & Itália & Selinunte & $\mathrm{C}$ & $6 \times 17$ & $23,937 \times 63,720$ & \begin{tabular}{|l|}
8,653 \\
\end{tabular} & 4,480 & mesma \\
\hline 540 & & Turquia & Assos & Atena & $6 \times 13$ & $14,030 \times 30,310$ & 4,780 & 2,02 & $"$ \\
\hline 540 & & Grécia & Corinto & Apolo & $6 \times 15$ & $21,484 \times 53,824$ & 7,240 & $?$ & " \\
\hline 535 & & Itália & Selinunte & $\mathrm{D}$ & $6 \times 13$ & $23,626 \times 55,679$ & 8,310 & 3,953 & " \\
\hline 530 & & Itália & Pesto & Basílica & $9 \times 18$ & $24,510 \times 54,270$ & 6,445 & $?$ & $?$ \\
\hline 525 & & Itália & Selinunte & FS & $6 \times 14$ & $24,370 \times 61,880$ & 9,110 & 3,955 & mesma \\
\hline 529 & 515 & Grécia & Atenas & Atena (Pisistrátidas) & $6 \times 12$ & $21,300 \times 43,150$ & ca. 7,400 & 3,999 & " \\
\hline 520 & 450 & Itália & Selinunte & Apolo (GT) & $8 \times 17$ & $50,070 \times 110,120$ & 14,690 & 6,560 & $"$ \\
\hline 510 & 409 & Itália & Agrigento & Zeus Olimpico & $7 \times 14$ & $52,740 \times 110,095$ & 17,265 & 7,555 & $"$ \\
\hline 510 & & Itália & Pesto & Deméter & $6 \times 13$ & $14,541 \times 32,880$ & 6,127 & 2,653 & " \\
\hline 500 & & Itália & Metaponto & Tavole Paladine & $6 \times 12$ & $16,060 \times 33,460$ & 5,135 & $?$ & $?$ \\
\hline 500 & & Itália & Agrigento & Héracles & $6 \times 15$ & $25,284 \times 67,040$ & 10,070 & 3,710 & mesma \\
\hline 500 & & Grécia & Delfos & Atena Pronaia & $6 \times 12$ & $13,250 \times 27,464$ & 4,600 & $?$ & " \\
\hline 498 & & Grécia & Súnio & Posidon (Antigo) & $6 \times 13$ & $13,060 \times 30,200$ & $?$ & $?$ & $"$ \\
\hline 495 & 485 & Grécia & Egina & Afaia & $6 \times 12$ & $13,770 \times 28,815$ & 5,272 & 1,966 & 2,041 \\
\hline 488 & 480 & Grécia & Atenas & Partenon (Antigo) & $6 \times 16$ & $23,533 \times 66,940$ & $?$ & $?$ & $?$ \\
\hline 480 & & Itália & Siracusa & Atena & $6 \times 14$ & $22,000 \times 55,020$ & 8,710 & 3,900 & $?$ \\
\hline 480 & & Itália & Himera & Nike & $6 \times 14$ & $22,455 \times 55,955$ & $?$ & $?$ & $?$ \\
\hline 480 & 460 & Itália & Selinunte & Hera (ER) & $6 \times 15$ & $25,324 \times 67,735$ & 10,150 & 4,470 & mesma \\
\hline \begin{tabular}{l|l}
468 \\
\end{tabular} & 460 & Grécia & Olimpia & Zeus & $6 \times 13$ & $27,680 \times 64,120$ & 10,430 & 4,080 & 4,155 \\
\hline $460-454$ & $314-280$ & Grécia & Delos & Apolo & $6 \times 13$ & $12,470 \times 28,530$ & 5,200 & 2,060 & $"$ \\
\hline \begin{tabular}{l|l}
460 \\
\end{tabular} & & Itália & Pesto & Posídon & $6 \times 14$ & $24,264 \times 59,975$ & 8,880 & 3,788 & mesma \\
\hline 460 & & Itália & Agrigento & Hera Lacinia & $6 \times 13$ & $16,910 \times 38,100$ & 6,360 & 2,900 & " \\
\hline 460 & & Itália & Selinunte & A & $6 \times 14$ & $16,129 \times 40,303$ & 6,235 & 2,780 & " \\
\hline 450 & 425 & Grécia & Bassai & Apolo & $6 \times 15$ & $14,478 \times 38,244$ & 5,957 & 1,948 & $"$ \\
\hline 449 & 444 & Grécia & Atenas & Hefesto & $6 \times 13$ & $13,708 \times 31,769$ & 5,713 & 2,020 & 1,980 \\
\hline 447 & 432 & Grécia & Atenas & Partenon & $8 \times 17$ & $30,880 \times 69,503$ & 10,433 & 3,295 & mesma \\
\hline 444 & 440 & Grécia & Súnio & Posidon (novo) & $6 \times 13$ & $13,470 \times 31,124$ & 6,024 & 2,010 & 1,990 \\
\hline 440 & 436 & Grécia & Atenas & Ares & $6 \times 13$ & $14,344 \times 33,174$ & 6,275 & 2,027 & 1,967 \\
\hline 436 & 432 & Grécia & Rhamno & Nêmesis & $6 \times 12$ & $9,996 \times 21,420$ & 4,100 & 1,394 & 1,356 \\
\hline 430 & & Itália & Agrigento & Concórdia & $6 \times 13$ & $16,925 \times 39,42$ & 6,700 & 2,960 & mesma \\
\hline 425 & 417 & Grécia & Delos & Apolo ou dos Atenienses & 6 Anfiprost. & $9,686 \times 17,014$ & 4,650 & 1,476 & $"$ \\
\hline 424 & 416 & Itália & Segesta & Inacabado & $6 \times 14$ & $23,120 \times 58,035$ & 9,366 & 3,585 & " \\
\hline 423 & 416 & Grécia & Argos & Heraion & $6 \times 12$ & $17,305 \times 36,900$ & ca. 7,400 & 2,480 & " \\
\hline 380 & & Grécia & Epidauro & Asclépio & $6 \times 11$ & $11,760 \times 23,060$ & 5,200 & 1,520 & $"$ \\
\hline 366 & 326 & Grécia & Delfos & Apolo & $6 \times 15$ & $21,680 \times 58,180$ & 10,590 & $?$ & $"$ \\
\hline 350 & & Grécia & Tegéia & Atena Aléia & $6 \times 14$ & $19,190 \times 47,550$ & 9,474 & 2,421 & 2,352 \\
\hline 340 & & Grécia & Neméia & Zeus & $6 \times 12$ & $20,090 \times 42,555$ & 10,368 & 2,567 & 2,484 \\
\hline 321 & & Grécia & Estratos & Zeus & $6 \times 11$ & $16,570 \times 32,420$ & 7,095 & 2,071 & mesma \\
\hline 320 & & Grécia & Olimpia & Metrôon & $6 \times 11$ & $10,620 \times 20,670$ & $?$ & 1,488 & u \\
\hline 250 & & Turquia & Pergamo & Atena Polias & $6 \times 10$ & $12,270 \times 21,770$ & 5,260 & 1,225 & $"$ \\
\hline 170 & & Turquia & Pergamo & Dioniso (Market t.) & 4 Prostilo & $6,765 \times 10,135$ & 4,490 & 0,850 & " \\
\hline
\end{tabular}

Fonte: Dinsmoor (1950, p. 337-339, entre p. 340 e 341).

\footnotetext{
${ }^{12}$ Tabela elaborada a partir da edição de duas listas de Dinsmoor (1950). Entab = entablamento (dimensões em metros).
} 
Figura 2 - Ordem dórica (templo de Aphaia, Egina) 500-480 a.C.

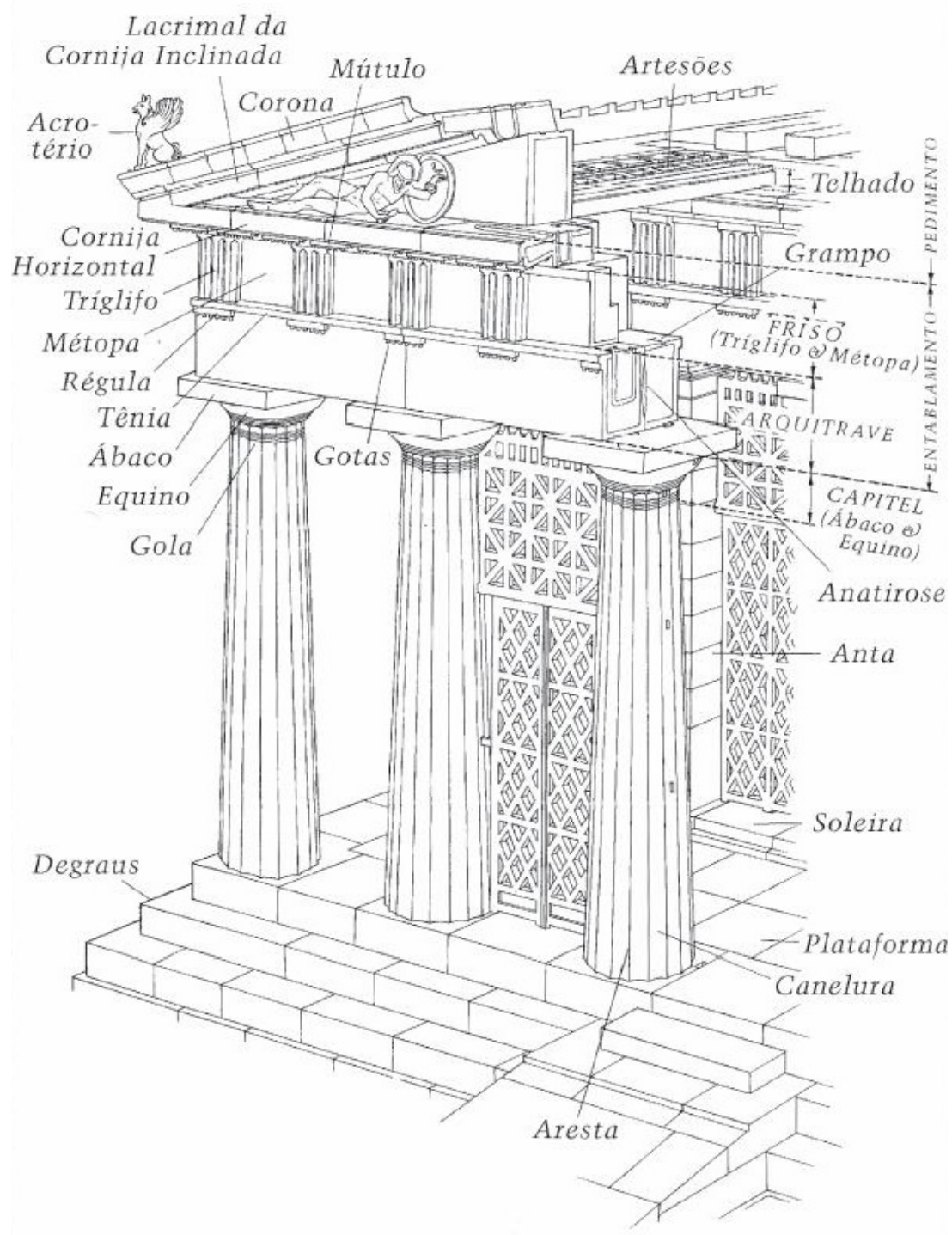

Fonte: Lawrence (1988, p. XIV). 